
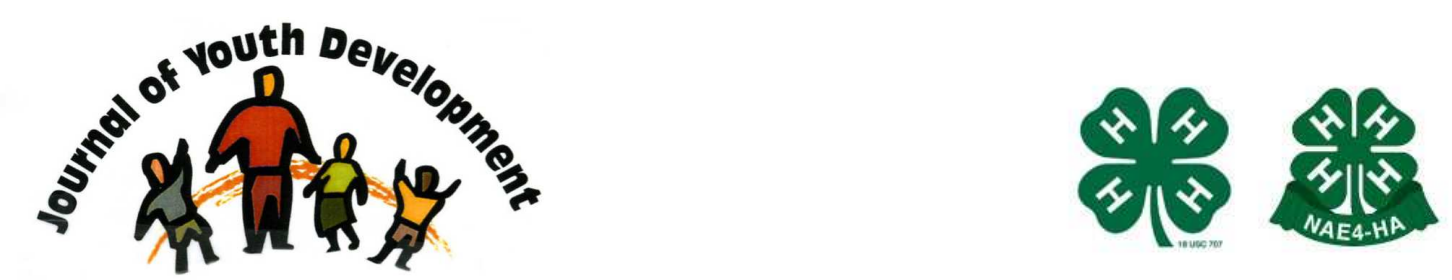

Bridging Research \& Practice

\title{
The Future of Youth Development: Multiple Wisdoms, Alternate Pathways and Aligned Accountability
}

Dale A. Blyth

University of Minnesota

blyth004@umn.edu 


\title{
JOURNAL OF YOUTH DEVELOPMENT \\ bridging research and practice

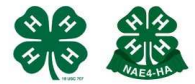

\section{The Future of Youth Development: Multiple Wisdoms, Alternate Pathways and Aligned Accountability}

\author{
Dale A. Blyth \\ University of Minnesota
}

\begin{abstract}
Based on trends and events observed or experienced by the author over the last 30 years in research, evaluation and practice, this article examines three challenges facing and shaping the future of the youth programs as contexts for development. The first challenge surrounds how the field comes to understand, value and integrate different forms of knowing -- particularly quantitative data. The second challenge represents how the field shifts from proving it makes a difference to improving the ways it makes a difference by expanding the pathways to impact. The third challenge regards how the field responds to and shapes accountability pressures in ways that better align accountability rather than succumb to it. Implications of each challenge for effectively bridging research and practice are noted.
\end{abstract}

\section{Introduction}

This is not an article about predicting the future. That's a risky business at best and not one in which I claim expertise. But just as it is important to look back over the last one hundred years of progress in understanding youth development, it is also important to look forward. What factors could, should or simply will shape the research, practice, programs, public will and policy surrounding non-formal learning and youth development programs in the future? Some of these factors will originate and be nurtured within the field while others will likely arise externally and have significant influence.

This article deliberately focuses on youth programs as contexts for development and the various ecologies that shape programs. By youth programs I am referring to intentional programs that use a non-formal, youth-centric approach to learning and development rather than youth development as a philosophy or an approach, a distinction that emerged at a conference focused on building the field of youth development and is captured in Hamilton and Hamilton (2003). This is done to shift the focus away from adolescent development in general and from the full breadth of family and community influences on youth development that are critically important but not all programmatic in nature. The shift to youth programs as contexts for 
development and their ecology brings more focus to the field as a deliberate form of practice. It also enables sharper focus on such issues as the professional development of the youth workers who make programs happen and the community, organizational, system and policy ecologies in which programs operate.

In my view, a series of shifts makes this focus on programs and systems appropriate. These shifts will be briefly examined from the perspectives of my lived experience in the field for over thirty years. The article then explores three challenges the field must address as a result of these shifts and related changes in expectations. Each challenge informs both the types of research and evaluation that will be required to move forward as well as specific implications for bridging research and practice effectively. The challenges address the importance of using multiple sources of wisdom, of exploring alternative pathways to impact, and of dealing with accountability. In this way I hope to identify those forces and factors that have and likely will shape the future of our field and reflect on how we might utilize them in ways that matter for improving the quality, accessibility, and impact of youth programs - and thereby increase critical learning and developmental outcomes for youth.

\section{Recent Shifts Affecting the Field}

Within the latest thirty years major shifts in the field of youth development have often been caused by or generated new research and evaluation. My perspectives and understandings of these shifts were created or influenced by my personal experience as a leader, participant, and observer over time.

These shifts include such things as

- the growth of program evaluation as a field and profession since the 1970 s in ways that advanced the systematic use of data for assessing and improving impact;

- the creation of the Society for Research on Adolescence ${ }^{1}$ in 1984 and the creation of multiple journals and edited volumes which helped increase the quality, interdisciplinary nature and visibility of research on young people;

- the work of the William T. Grant Commission on Work, Family and Citizenship (1988) report The Forgotten Half that showed higher education was not reaching all youth, and helped identify the need to understand major differences among American youth's pathways to adulthood;

- the rise of strength-based approaches in the 1990s (especially the Search Institute assets model ${ }^{2}$ ) which helped make development as important a frame as prevention and intervention;

- the work of the Carnegie Council on Adolescent Development and its influential report, $A$ Matter of Time, (Quinn \& Takanishi, 1992) which brought attention to the importance of out of school time for learning and development;

- the creation of the Center for Youth Development and Policy Research at the Academy for Educational Development that provided leadership and a visible national hub for this work;

- the series of studies by Public/Private Ventures (e.g. Tierney \& Grossman, 1995) on mentoring and other youth and community development programs that both proved the value of programmatic efforts and provided guidance on improving practice;

- the call by Karen Pittman and the Forum for Youth Investment to systematically move beyond problem free to fully prepared and fully engaged ${ }^{3}$ which emphasized the importance of the broader community and policy role in youth development; 
- the work of Della Hughes, the National Network of Homeless and Runaway Youth, and the creation of the CYD Journal ${ }^{4}$ in the 1990s that, along with others, emphasized the combination of youth and community development;

- the growth of the service-learning movement and the value of civic engagement led by Kellogg Foundation investments ${ }^{5}$ and the National Youth Leadership Council among others, which held up youth as contributors and resources not just participants;

- the investments during the 1990s by the then Dewitt Wallace-Readers Digest Fund in the professional development of youth workers in multiple youth-serving organizations and systems that promoted systematic examination of the field and the programs and people who run them;

- the increase in other private and federal funding for youth development in the 1990s and the first decade of the $21^{\text {st }}$ century including the Mott Foundation and federal $21^{\text {st }}$ Century Community Learning Centers in the afterschool area;

- the publication of Youth Development: Issues, Challenges, and Directions ${ }^{6}$, which gave voice to the field through essays by multiple leaders;

- the creation of a National Youth Development Clearinghouse and Research Council at the National Collaboration for Youth, which helped gather our fugitive literature and unite the researchers and evaluators inside national youth organizations;

- Richard Lerner's editorial leadership and writing over the years and the Tufts University 4-H study of positive youth development that helped to measure key concepts and explore different trajectories of development ${ }^{7}$;

- the emergence of multiple undergraduate and graduate programs for youth development practitioners and researchers, including the M. Ed. in Youth Development Leadership at the University of Minnesota, that helped educate a generation of leaders in the field;

- a number of foundation investments in community youth development efforts, most notably the Kellogg ${ }^{8}$ Foundation's Kellogg Youth Investment Partnerships, that worked to deeply change the community ecology for youth;

- the Michelle Gambone and James Connell work (e.g. Gambone, Klern, \& Connell, 2002) on the difference supports and opportunities make, that provided a framework and evidence for community approaches;

- the release of the Eccles and Gootman National Research Council - Institute of Medicine report Community Programs that Promote Youth Development in 2002 that gave scientific credibility to youth programs in new ways and created a language and a framework for thinking about the characteristics of youth programs that were likely to make a difference;

- the Wingspread Conference (Garza, Borden, \& Stone, 2004) and eventual creation of the Next Generation Youth Work Coalition that helped us see professionals in our through the lens of workforce development ${ }^{9}$;

- the development and resourcing of studies on youth programs as contexts for development by the W. T. Grant Foundation (1988);

- the work of Reed Larson and his colleagues looking inside youth programs as contexts for development that provided new insights into developmental processes occurring in programs with implications for practice;

- the development of multiple ways to assess quality and the work of the Weikert Center for Youth Program Quality on quality improvement approaches and systems ${ }^{10}$;

These people, organizations, ideas, and publications, in combination with many other efforts, helped changed how I have come to see the field. They helped me move from a broad but ambiguous sense of the importance of community in youth development to a more focused 
effort to understand public perceptions of what youth need to succeed. They helped me move from a broad sense of the importance of informal opportunities that communities can provide to a more focused sense of how we design and deliver deliberate non-formal community learning opportunities through programs.

These influential contributions allowed me to reframe my thinking and move from a fairly narrow focus on programs where youth become engaged in their own learning and development to a larger understanding of ways to shape the people and systems that support opportunities in the community. It is not that I no longer believe in the importance of informal community and family influences on development. Rather, I have come to see youth workwith a deliberate focus on the role of non-formal community learning opportunities that are intentional contexts of development and on system approaches in communities that support them-as the best way to shape an applied field that can make a difference in the lives of youth.

These shifts have also created new expectations. Youth development has moved into what I call the "major leagues." We're no longer playing in the minors; our work now is commonly brought up in major conversations around education, learning, community development and health. These efforts helped earn community youth programs a seat at bigger tables with a role to play that is more necessary than simply nice. And with this shift to major league status comes increasing expectations-expectations for greater accountability for greater quality; for certification of professional practitioners and accreditation of programs; for more systematic and public policy supports for such efforts; and for increased use of data and evidence in the design and operations of youth programs.

All these expectations increase the role research and evaluation can play in our field as well as fundamentally alter how we think about bridging research and practice. How the field of youth development-with its variety of programs, multiple types of professionals, and diverse workforce of full, part-time, and voluntary practitioners-works to meet these expectations is the key to its future. The ways in which this plays out are likely to be shaped by how the field addresses three major challenges.

\section{Three Challenges Moving Forward}

Based on these reflections, my participation in some of the major forces shaping youth development over the last thirty years, and my efforts to create and lead a statewide, university-based intermediary for more than a decade, three clear challenges have emerged:

- Valuing, nurturing and integrating multiple forms of wisdom

- Exploration of alternative pathways to impact, and

- Alignment of different forms of accountability.

The ways we think about both research and practice, and the bridge between them, in the years ahead will be shaped by these fundamental challenges.

\section{Challenge 1: Recognition and Integration of Multiple Forms of Wisdom}

Wisdom comes in many forms and from multiple ways of knowing. The goal of wisdom, and in my view research and evaluation in our field, goes beyond understanding child and adolescent development. It means applying research and evaluation in practice that makes a difference in the learning and development of young people as they engage as learners, contribute as citizens, navigate their present and plan their future. In a field that has historically grown largely from practical wisdom, the future lies not in discarding such wisdom but embracing, 
documenting, and integrating it with multiple other types of wisdom. We must broaden our approaches to discovery and understanding and then make the most of the data we gather to strengthen practice, stimulate new research, and impact youth policy and funding for the field.

Empirical research and program evaluations using both qualitative and quantitative methodologies have stimulated much of the progress in our field over the last 30-plus years. To its credit, much of this work has been interdisciplinary and multi-disciplinary by nature and includes developmental and community psychology, sociology, education, prevention science, economics, evaluation, communications, social work, and policy research. Because empirical studies are widely accepted as the coin of the realm in the "major leagues," we must become more adept at using quantitative data in particular to make our case and document our progress in reaching our goals.

Cultural, community and participant wisdom is also essential. Even the best forms of empirical research can have limited meaning without an understanding of different cultural and community contexts. Understanding those contexts and their implications for young people and for youth programs is critical and needs to include understanding the ways in which cultures grow and develop inside of youth programs and organizations. But to succeed, we must include the wisdom of young people themselves. As co-creators and participants in youth programs, young people have unique perspectives and valuable insights into what is happening and why. While we cannot simply defer to their wisdom, we can also not afford to ignore it if we are to grow as a field. Youth as colleagues in building our field is one of the greatest untapped resources available.

Together these multiple types of wisdom can help youth programs attract, retain, engage, and impact youth and assure the quality, accessibility, efficiency, and effectiveness of program efforts. When we see value only in one or two of these approaches to understanding and discovery, we are shortchanging the field and depriving it of needed insights and the power of integrated ways of knowing.

Implicit in this challenge for bridging research and practice is our dedication to the growth of each as well as the integration of different forms of wisdom. Internal and external opportunities that promote this robust research-practice integration include the preparation of youth workers and the education of program leaders, researchers and evaluators. Such integration depends on building theories, analogies and metaphors that connect across various audiences and represent various ways of knowing. This means moving from "framework wars" to "creative integration" where theories of learning and development for the whole child acknowledge the unique and common features of non-formal learning approaches and reinforce programs as valuable contexts for development. This includes theories that help us to make sense of what is known as well as to rethink our approaches to both practice and research.

An example of a useful metaphor that I have written about is one framed around developmental diet and exercise (Blyth, 2006). That framework looks at cumulative rather than single intervention approaches and is more consistent with what we know about development. It helps community leaders think about the accumulation of experiences, not just the impact of one program. It helps people better understand the complexity of development and what it takes to make a real difference. It can change the way we design research and the types of questions we ask. 
In reinforcing research-practice integration, our field needs to find ways for preparing practitioners to value, recognize, collect and utilize data in their practice in ways that are just beginning to appear ${ }^{11}$. Youth programs will not thrive in the major leagues if they do not track data better and analyze it more usefully. New data management systems available for organizations (such as 4-H OnLine ${ }^{12}$ ) and used in major cities (such as YouthNet ${ }^{13}$ in Providence) now allow very innovative ways to track participation and survey youth.

It is of growing importance to prepare and support "bilingual bridgers" or "translators" who can move across systems and help integrate different forms of wisdom. They work to bring out commonalities that connect different forms of wisdom into practice and lead multiple forms of practice to inform new questions for research. One way for these bridgers to reinforce researchpractice integration is to shape the publications and reading that is encouraged in the field. People in the field benefit from exposure to a range of journals and other publications, but there is a special need for those that integrate different forms of wisdom and are accessible to the wide range of professionals in youth work. Publications that are peer reviewed but not constricted by overly narrow distinctions between scholarly and applied research or between critical reflection, practice and evaluation will be especially important.

In summary, our efforts to address this challenge will require us to find a better balance in how we come to understand and use what will make a difference. It will require placing more value on quantitative data and the valid and reliable measurement of core concepts while not decreasing the value and richness of qualitative data and the learning that comes from practice. We must not surrender to a simple bookkeeping approach to youth work but also recognize the value of data that captures outcomes, assesses quality, measures engagement, and is useful in policy as well as program improvement circles.

\section{Challenge 2: Exploration of Alternative Pathways to Impact}

Over several years as I have spoken to various groups, I have come to frame the future of youth programs and their ability to make a difference for young people in primarily two ways that aim to unite around a focus on increasing impact but avoid overly simplistic answers to which people often leap.

The first way talks about moving from the additive model of the past to a multiplicative model for the future. In the past we primarily thought about increasing the impact of youth programs by adding more programs. While there is often a demonstrated need for more programs especially in opportunity-depleted communities or to deal with inequities in access within a community, research suggests it is no longer sufficient to think in these simple additive terms.

Instead, the evidence suggests that it is time to move to a more multiplicative model of impacta model that recognizes and brings into one equation the various factors that research shows contribute to a program's impact. The equation I have come to use to represent this is

\section{Where}

$$
\text { RI = PD } \times \text { A } \times \text { QP } \times \text { YE }
$$

RI represents the $\boldsymbol{R e a l}$ Impact experienced by a youth in a program

PD represents Program Design features that enhance the potential for impact

A represents a youth's Access to and participation in the program

QP represents the Quality of Practice as actually delivered in the program

YE represents the individual Youth's Engagement in the program 
In this model, the impact of a program on a given young person is a dynamic function of how the program is designed, whether and to what extent they can access it and participate, the quality practiced at the point of service, and the level of cognitive and socio-emotional engagement the young person experiences. To be clear, this equation only assesses the impact of a program, not the impact of communities, families and other factors present in the youth's life. While our field is not yet ready for a more comprehensive mathematics of development, this formula for seeing program impact in terms of a multiplicative model has utility for expanding the ways we think about impact.

These factors are interactive. For example, the program's design may increase participation and engagement while the quality of practice may increase the level of a youth's engagement. Absence of any factor means multiplication by zero and thus no impact. Youth who cannot access a program cannot be positively impacted by it. Programs that have no structure or design features that matter are unlikely to have impact. Poor quality can not only eliminate positive impact but actually have negative impacts.

The equation reminds us that some of the factors affecting impact are characteristics of the program and the quality practices within it, others are a function of factors affecting access to the program, and others are unique for each youth. This richer but more complex model illustrates that we can to shift the "math" from simply adding more programs to working on the various factors that can improve the impact of programs. It also begins to delineate possible alternative pathways through which to improve impact as will be noted later.

The second way I frame the conversation about the future of our field emphasizes the need to shift from proving impact to improving impact. The latter requires us to explore alternative pathways for impact. Currently too much pressure is placed on programs to either (1) prove they deliver specific outcomes, especially outcomes too narrowly defined or not fully appropriate for youth programs, or ( 2) prove they have a positive economic return on investment. The first point illustrates the push to assess the value and contributions of youth programs using only formal educational outcomes such as grades and test scores; whereas, the second point illustrates the push to attribute cost values to bad outcomes such as delinquency while under valuing youth engagement and their contributions to community.

As noted in Blyth and LaCroix-Dalluhn (in press) such pressures too often distort what happens in research (what we study) and practice (what we do in youth programs). Such distortion, in my view, inhibits our search for ways to improve impact. To be clear, I do believe as a field we need to measure outcomes and to assess costs and benefits-and we would be wise to do so even more systematically and less haphazardly in the years to come. However, these are not the only pathways to improving impact that our field needs to explore.

Only implementing proven practices, which is very hard to do with the fidelity needed to ensure impact, is both expensive and uneven in its success - especially in an unregulated and underresourced field such as youth development. Only funding programs with a proven economic return on investment requires years of work to understand the economic tradeoffs before one can make wise decisions about how to invest public resources. Both of those investments are needed in youth development programs but both are years away, hence the need to explore and exploit alternative pathways.

Certainly the exploration and implementation of alternative pathways will require serious research studies that get at outcomes. Such studies will be needed and are critical to clarifying 
these pathways and their promise. Research that more systematically looks at what factors make a difference in programs that produce good outcomes and the extent to which various professional development efforts or systems support real changes in practice will prove very valuable to the field. In a sense, this approach moves our field from being stuck in a defensive posture of trying to prove that what we do can make a difference to improving the way we do it and increasing the probability of positive outcomes.

One reason for this shift is my belief that our field is already, and likely to stay, under-resourced in evaluation and research funds. Too often the expectations for outcome evidence is radically out of line with the resources needed to prove impact or economic benefits. Thus, asking each program to continually prove their outcomes for youth is both an unreachable and inefficient approach.

Another reason is that over the last 20 years, and especially in the last 10, the evidence that high quality youth programs of various types can impact youth outcomes is quite clear across a broad array of academic, cognitive, prevention, and socio-emotional outcomes (e.g. Durlack \& Weissberg, 2007; Little, Wimer, \& Weiss, 2008; Vandell, Reisner, \& Pierce, 2007). Proving outcomes are possible is no longer the appropriate main driver for research and evaluation about youth programs. More critical in my view are studies that begin to understand the relationship between the factors in the Real Impact equation above and how they play out in practice.

Using the equation above and thinking in terms of factors that have a probability of increasing impact allows us to think of five alternative pathways for improving impact as illustrated in Figure 1.

Figure 1

\section{PATHWAYS TO INCREASING IMPACT OF YOUTH PROGRAMS}

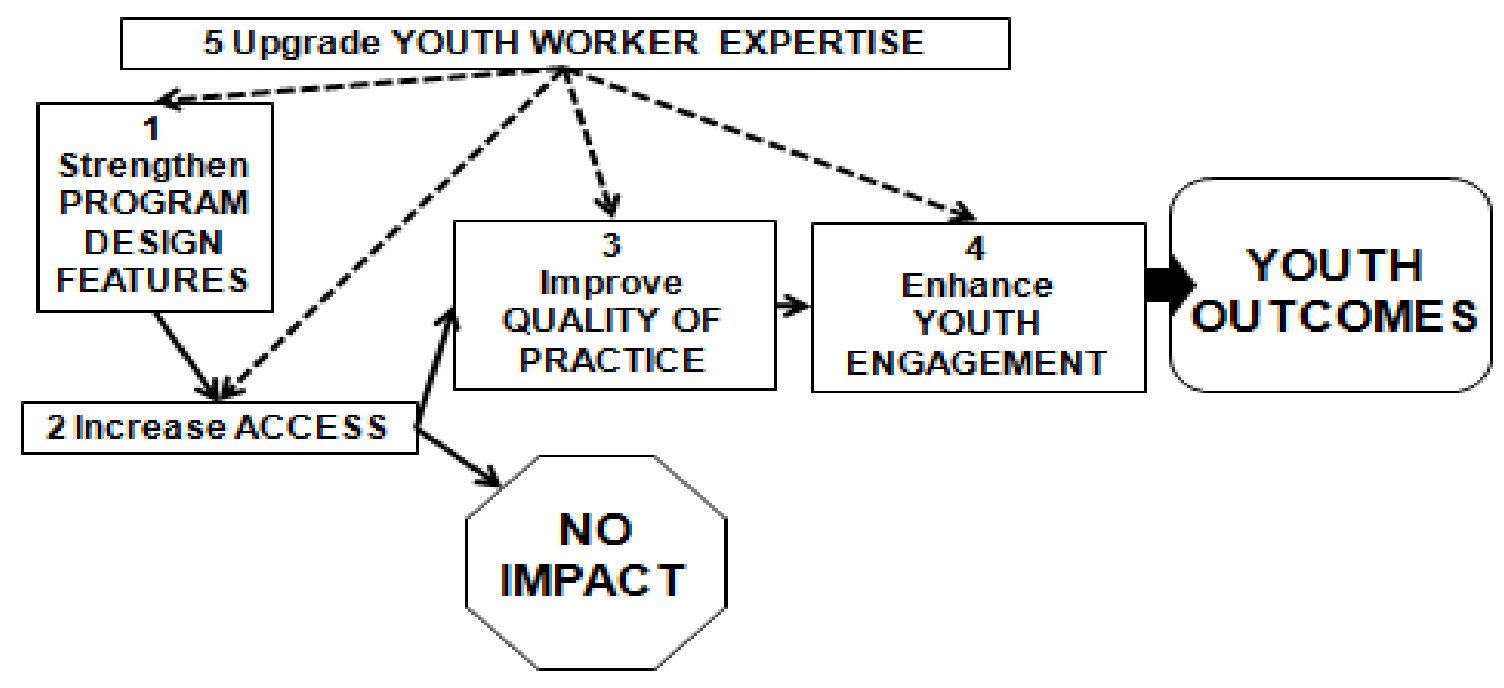


The model assumes the equation factors interact but have no independent direct effects (e.g., even the best designed program if youth cannot access it, it lacks quality or does not engage youth has little impact). Each alternate pathway is numbered in the diagram.

The first strategy or pathway is to improve the design of youth programs so they have more of the features that research and practical wisdom suggest have impact. These are the types of features highlighted in the Eccles and Gootman report (2002). For another example see Durlack and Weissberg's (2007) SAFE model. This pathway involves bridging research and program design in new ways and with better empirical understanding of "best", proven, and promising practices. This pathway is commonly in the hands of program developers who select the strategies and activities that make up a given program

The second pathway involves changing the accessibility of the program and the level of a youth's participation in the program. While participation could appropriately be thought of as yet another factor made up of frequency, duration and intensity, I have chosen to include it in access since the same issues affecting access often affect participation (e.g., transportation, affordability, and availability). In a recent article (Blyth \& LaCroix-Dalluhn, in press) my coauthor and I argue that the inequalities in access to non-formal and informal community learning opportunities are likely greater than in formal learning opportunities through school and a significant factor contributing to educational disparities. As such inequalities beyond the classroom represent an important opportunity gap that must be closed. If we want to improve the impact of non-formal learning opportunities on youth in any number of areas, we must reduce these inequities and promote equal access and opportunities to participate at levels high enough to make a difference. This pathway builds on and needs additional research about what types of impacts community and system change efforts, such as those by the intermediaries that are part of the Collaborative for Building Afterschool Systems (CBASS) ${ }^{14}$, have on access and participation. For recent excellent example of such a study see Kauh (2011).

The third pathway requires improving the quality of practice at the point of service or as actually implemented. This pathway relies on the growing literature on the importance of quality and its increasing measurability and malleability (Yohalem \& Wilson-Ahlstrom, 2009). Note that the first pathway depends on incorporating sound research-based design features into the program plan. This third pathway relies on fidelity of implementation of those features of practice that research has shown strongly connect quality measures to actual program outcomes. Here the key players for practice are the middle managers and front-line staff that shape what happens at the "point of service" where youth experience the program. To more effectively exploit this pathway we likely need more efficient and effective use of quality measures that become more fully integrated into the routine assessment and monitoring of programs. Minnesota 4-H has launched just such an effort using both adult and youth volunteers to rate quality. The early evidence from this work indicates that quality observation and assessment approaches are motivating to many practitioners, unlike typical outcome studies, because they provide guidance on how to improve their practices not just judge them by a limited set of results (Moore, Grant, McLaughlin, Walker, \& Shafer, 2010). Research is needed in this area that more strongly links elements of quality to various forms of outcomes.

The fourth pathway relies on better understanding and promoting youth's engagement in programs. This is heavily influenced by and built into some of the higher level definitions of quality such as the Weikert Center's Youth Program Quality Assessment ${ }^{15}$. It is, however, distinct for our purposes here as it is a characteristic of an individual youth, not the observable "general" practice going on in the program. Here new frameworks for thinking about youth 
engagement (Sullivan, 2011) begin to pull apart participation from connection, voice, and collective action. This pathway is one that will likely require greater intentionality from multiple players. One of the most intriguing is the possibility of using levels of youth engagement in youth programs as a major outcome variable for both programmatic and policy purposes. This area, along with the assessment of youth contributions, holds great promise for future research as well as system change efforts.

The final alternative pathway requires upgrading the expertise of youth workers. This pathway can have impact on multiple other pathways as indicated in Figure 1. It assumes that we are able to help youth workers at various levels and in various programs become more intentional in appropriate ways and use data effectively to make changes that will improve impact. The support of these types of changes is likely to involve some combination of increasing core competencies in youth workers as well as increasing their expertise in seeing situations differently, diagnosing what is happening, and implementing different approaches in real time (Walker \& Walker, in press). Research and evaluation in this area are badly needed.

The role of the different types of wisdom and the different types of empirical research and evaluation needed to move the field along these multiple alternative pathways is complex and challenging; some of it is already underway, but much more is needed. Which pathways get the most attention and how they use strong empirical research are likely to evolve over time. One of the major factors affecting that evolution is how we respond to the third challenge-the alignment of accountability practices.

\section{Challenge 3: Alignment of Different Kinds of Accountability}

With the expansion of the number of pathways for improving impact comes the need for better aligning different types of accountability across various levels of policy, program, and practice. Our current accountability systems seem to be driven primarily by evidence of program level outcomes. This leads government and some private funders to insist upon supporting only "evidence-based" programs with a sufficient level of rigor in research and evaluation to "prove" the program produces a set of known outcomes. Depending on the availability of research resources for such studies and the appropriateness of randomized control experimental designs, it is very hard to produce such evidence. More importantly, it is very hard to effectively bridge it into practice in a field with highly variable types of programs and wide diversity in how they are implemented across sites. Without high fidelity to the model, these models provide little improvement in outcomes.

One could argue that this type of accountability is unlikely to be successful in a field such as youth development where there is a relatively low level of public investment and regulation, high variability in program designs and quality of practice, a varied paid and volunteer workforce with few credentials or certified competencies, with the youth in the program voluntarily and themselves dynamic factors in the program's effectiveness. Such conditions certainly complicate effectively improving impact but more important for the argument here is that they restrict themselves to only one or two forms of accountability even though they are unlikely to be successful.

I have come to believe, both in our field and for the broader efforts at producing desired outcomes for children and youth, that a new paradigm for aligning rather than selecting a narrow form of accountability is needed. Table 1 below illustrates how different forms of accountability might be aligned to improve the probability that what is done in our field has increased impact. 
Table 1

Sample Way of Aligning Accountability

\begin{tabular}{|l|l|}
\hline Accountability for ... & Level Responsible \\
\hline Selecting Outcomes & Policy Level \\
\hline Monitoring Outcomes & Geographic Levels \\
\hline Effective Strategies & System Level \\
\hline Improving Access & System Level \\
\hline Quality of Program & Organization Level \\
\hline Quality of Professional & Association Level \\
\hline
\end{tabular}

In the example, if the policy level was held accountable for establishing a clear set of desired outcomes that are needed for success in learning and development at different ages and in different areas, then other levels could be accountable in different ways. In part this is the logic behind efforts to change the odds that youth are "ready by 21 - ready for work, college and life" as the Forum for Youth Investment and its partners propose ${ }^{16}$. It is also the logic behind the Strive Foundation's efforts in collective impact (Kania \& Kramer, 2011).

If a clear set of outcomes existed and was regularly assessed in a community then other forms of accountability could be aligned to improve them. That could include holding geographic units such as cities or counties accountable for appropriately monitoring whether or not the outcomes improve, and adjusting strategies if they do not. It could include holding systems accountable for selecting and resourcing appropriate evidence-informed strategies and assuring youth have access to them. It could include asking the organizations involved in providing the programs to be accountable for the quality of the practice in their programs. Finally, it could include asking professional associations and organizations to be accountable for the competence and expertise of their practitioners.

In many ways this type of aligned accountability is what occurs in some more mature fields where more public resources are invested such that higher levels of accountability are expected. This might be seen as true for social work and early childhood care and education efforts to some degree. They are also seen in good business practices that hold some staff accountability for specific areas of work (quality, sales, etc.).

Currently we have an interesting opportunity for youth development to build a field where the alignment of accountabilities and the main pathways for improving impact work together in imaginative and effective ways. Such an effort will require the application of a rich array of empirical research and evaluation. Assuring that such research and evaluation is done, done 
well, and integrates and respects other forms of knowing may be the ultimate challenges for our field moving forward.

\section{Conclusion}

In summary, the field of youth development has experienced a series of significant shifts that bring it into the major leagues at a unique time of increased accountability; decreased public resources; mixed funding models of public, private, and personal/family resources; major changes in technology; and new forms of research and analysis. By focusing on youth programs as contexts for development and the community, organizational, system, and policy ecologies in which programs exist, these factors can allow the youth work field to "come of age" in new ways. Ways that are perhaps different than fields that matured much earlier in times that preferred government regulations, had expanding public resources, or more limited views of what health and education mean.

Whether we as a field can take advantage of this unique combination of factors or succumb to narrow pressures is in part for us to determine through the ways we do research and proactively bridge research and practice. Whether around program designs, studying systems in communities, or shaping the quality of practice and the preparation of practitioners, the role of research and practice integration-deliberate bridging-is the key to our field's future. The way we bring these various forces together to create a coherent field made up of many allied professionals, multiple organizational and community systems, and a workforce that can deliver on the promise of youth programs is critical. The role of researchers, practitioners, and most especially the "bilingual bridgers" who move between these and the world of policy and organizational leadership is particularly important if our field is to thrive going forward. The three challenges delineated here, and their implications, can positively influence and stimulate the ways we respond. If our field can become guided by wisdom that comes from knowledge in many forms, that thinks about multiple pathways to improvement, and that seeks to align rather than select a single form of accountability; our field will be stronger and the impact of opportunities for young people greater. I am excited by our challenging present and optimistic for the future of youth development as the bridging of research, practice, programs, policy and public understanding seek to rise to the occasion over the next 100 years.

\section{References}

Benson, P.L., Leffert, N., Scales, P.C., \& Blyth, D.A. (1998). Beyond the village rhetoric: Creating healthy communities for children and youth." Applied Developmental Science, Vol.2, No. 1: 138-159.

Blyth, D. (2006). Toward a new paradigm for youth development. In Rethinking programs for youth in the middle years. Special Issue of New Directions in Youth Development.

Blyth, D., \& Walker, J. (Number 112, Winter 2006). Jossey-Bass Publisher.

Blyth, D., \& LaCroix-Dalluhn, L. (in press). Expanding the learning day: Key principles, driving perspectives, and major challenges. To appear in Fall 2011 special issue of New Directions in Youth Development.

Durlack, J.A., \& Weissberg, R.P. (2007). The impact of after-school programs that promote personal and social skills. A publication of the Collaborative for Academic, Social, and Emotional Learning (CASEL) available at 
http://www.wtgrantfoundation.org/publications and reports/browse reports/durlak weissberg after school.

Eccles, J.S., \& Gootman, J.A. (Eds.). (2002). Community programs to promote youth development. Washington, DC; National Academy Press.

Gambone, M.A., Klern, A.M., \& Connell, J.P. (2002). Finding out what matters for youth: Testing key links in a community action for youth development. Available at http://www.ydsi.org/ydsi/pdf/WhatMatters.pdf

Garza, P., Borden, L., \& Stone, B. (2004). Attracting, developing \& retaining youth workers for the next generation. Wingspread Conference proceedings, November 16-18, 2004. Available at http://www.nextgencoalition.org/docs/wing-report.pdf

Hamilton, S.F., \& Hamilton, M.A. (2003). The youth development handbook: Coming of age in American communities. Sage Publishing.

Kania, J., \& Kramer, M. (2011). Collective Impact. Stanford Social Innovation Review. Pp 36-41.

Kauh, T.J. (2011). AfterZone: Outcomes for youth participating in providence's citywide after-school system. Public/Private Ventures, Philadelphia, PA.

Leffert, N., Benson, P.L., Scales, P.C., Sharma, A.R., Drake, D.R., \& Blyth, D.A. (1998). "Developmental assets: Measurement and prediction of risk behaviors among adolescents." Applied Developmental Science, Vol.2, No. 4: 209-230.

Little, P.M.D., Wimer, C., \& Weiss, H.B. (2008). After school programs in the 21st century: Their potential and what it takes to achieve. In Issues and Opportunities in Out of School Time. Number 10. Harvard Family research Project. Available at http://hfrp.org/out-of-schooltime/publications-resources/after-school-programs-in-the-21st-century-their-potential-and-whatit-takes-to-achieve-it

Moore, D., Grant, S., McLaughlin, C., Walker, K., \& Shafer, B. (2010). Preliminary findings from the Minnesota 4-H quality improvement study: Using youth and adult volunteer assessors to take quality improvement to scale. Published by the University of Minnesota Extension Center for Youth development, Minneapolis, MN. Available at http://www1.extension.umn.edu/youth/docs/Minnesota-4-H-Quality-Improvement-Study.pdf

Pittman, K., Irby, M., \& Ferber, T. (1998). Unfinished business: Further reflections on a decade of promoting youth development. Published by The Forum For Youth Investment, Takoma Park, Maryland and available at http://www.forumfyi.org/files/UnfinishedBusiness.pdf

Public/Private Ventures (Eds.). (2000). Youth development: Issues, challenges and directions. Published by Public/Private Ventures, Philadelphia, PA and available at http://www.ppv.org/ppv/publications/assets/74 publication.pdf 
Quinn, J., \& Takanishi, R. (Eds). (1992). A matter of time: Risk and opportunity in the nonschool hours. A Publication of the Carnegie Council on Adolescent Development Task Force On Education Of Young Adolescents.

Scales, P.C., Benson, P.L., Leffert, N., \& Blyth, D. (2000). Contribution of development assets to the prediction of thrivingaAmong adolescents. Applied Development Science, vol.2, no. 1, 27-46.

Sullivan, T.K. (2011). Youth Engagement: More than a method. A way of life for healthy youth and community development. A white paper of the University of Minnesota Extension Center for Youth Development, Minneapolis, MN. Available at http://www1.extension.umn.edu/youth/docs/Youth-Engagement-More-than-a-method.pdf

Tierney, J.P., \& Grossman, J.B. (1995). Making a difference: An impact study of Big Brothers/Big Sisters. Public/Private Ventures. Philadelphia. PA.

Vandell, D.L., Reisner, E.R., \& Pierce, K.M. (2007). Outcomes linked to high-quality afterschool programs: Longitudinal findings from the study of promising afterschool programs. Available at http://www.policystudies.com/studies/?id=32

Walker, J.A., \& Walker, K.C. (in press). Establishing expertise in an emerging field. In Fusco, D. (Ed.). Advancing youth work: Current trends, critical questions. New York: Routledge.

William T. Grant Commission on Work, Family, and Citizenship. (1988). The forgotten half: Pathways to success for America's youth and young families. Washington, D.C.

Yohalem, N., \& Wilson-Ahlstrom, A. (2009). Youth program quality: A guide to assessment tools, $2^{\text {nd }}$ Edition. Published by The Forum For Youth Investment, Takoma Park, Maryland. Available at http://forumfyi.org/files/MeasuringYouthProgramQuality 2ndEd.pdf

\section{Footnotes}

${ }^{1}$ The society emerged out of a need for more opportunities to present and discuss the increasing volume of research on adolescent development and a series of Arizona meetings focused on applied research on adolescents. See http://www.s-r-a.org/ for information on the society and its biennial meeting.

${ }^{2}$ The work by Peter Benson and others at Search Institute to name and measure the assets young people need for positive development helped change both how we think about young people and how communities responded. Almost two million youth have completed its Attitudes and Behavior Survey around the world. See the series of three articles in Applied Developmental Science for research related to this work -- Scales et al. (2000), Leffert et al (1998), and Benson et al (1998).

${ }^{3}$ Karen Pittman and her colleagues' work over the years at the Academy for Educational Development, the federal government, the International Youth Foundation and the Forum for Youth Investment has been fundamental to the shift. See Pittman, K. Irby, M. and Ferber, T. (1998) and other related publications available at http://www.forumfyi.org/files/UnfinishedBusiness.pdf

${ }^{4}$ See http://www.cydjournal.org/archives/index.html for archives of this now defunct journal. 
${ }^{5}$ The $\$ 13 M$ W.K. Kellogg Foundation's "Learning in Deed" National Service Learning Initiative provides one of several examples noted here where a foundation's investment lead to major changes. See the report Retrospective Evaluation of K-12 Service-Learning projects, 1990-2000 available at http://www.wkkf.org/news/Articles/2002/10/Retrospective-Evaluation-Of-K-12-Service-Learning-Projects1990-2000.aspx. For more on the National Youth Leadership Council see http://www.nylc.org/about

${ }^{6}$ The edited volume (2000) Youth Development: Issues, Challenges and Directions provides a series of essays by leading figures in the field and helped unite efforts and clarify language in some areas.

${ }^{7}$ Richard Lerner has been a leading force in publishing in the field of youth development from creating journals to writing major books and studies. For an example see publications of the Institute for Applied Youth Development and the 4-H Study at http://ase.tufts.edu/iaryd/researchPositive4H.htm

${ }^{8}$ For more on this longer term effort to make three communities the best places on earth for youth to grow up see Kellogg Youth Initiative Partnerships (KYIP): Framework for the Future available at http://www.wkkf.org/knowledge-center/resources/2001/12/Kellogg-Youth-Initiative-Partnerships-KYIPFramework-For-The-Future.aspx

${ }^{9}$ For information on the Next Generation Youth Work Coalition go to http://www.nextgencoalition.org/

${ }^{10}$ See http://cypq.org/ for information about the Weikert Center for Youth Program Quality and its many publications and resources.

${ }^{11}$ For information on the National Institute on Out of School Time's Afterschool Matters Initiative and the Practitioner Fellowship see http://www.niost.org/afterschool-matters-initiative

12 For an example of emerging technology being used in some states by the 4-h program see https://www.4honline.com

${ }^{13}$ For information on an example of citywide data systems see https://www.youthservices.net/products.asp

${ }^{14}$ See http://www.afterschoolsystems.org/ for information about and publications of the Collaborative for Building Afterschool Systems.

${ }^{15}$ For information on this assessment tool go to http://cypq.org/products and services/assessment tools

${ }^{16}$ For information on the Ready by 21 Initiative and partnership see http://www.forumfyi.org/readyby21

(C) Copyright of Journal of Youth Development Bridging Research and Practice. Content may not be copied or emailed to multiple sites or posted to a listserv without copyright holder's express written permission. However, users may print, download or email articles for individual use. 